\title{
Perconditioning associated to hypertonic saline solution on liver function improvement after ischemia/reperfusion injury $^{1}$
}

Rubens Fernando Gonçalves Ribeiro Júnior', Rodrigo Paracampo Couteiro", Andrew Moraes Monteiro", Ivone Aline da Silva Rodrigues", Lainy Carollyne da Costa Cavalcante "II, Eduardo Henrique Herbster Gouveia"', Lucas Nascimento Galvão"I', Luiz Renato Oliveira Lopes", Edson Yuzur Yasojima'v, Marcus Vinicius Henriques Brito ${ }^{\text {IV }}$

'Fellow Master degree, Postgraduate Program in Surgery and Experimental Research, Universidade Estadual do Para (UEPA), Brazil. Statistical analysis, manuscript preparation, English language.

"Graduate student, School of Medicine, UEPA, Belem-PA, Brazil. Care of animals, technical procedures, interpretation of data, manuscript preparation.

"'Graduate student, School of Medicine, Centro Universitário do Estado do Pará (CESUPA), Brazil. Care of animals, technical procedures, interpretation of data, manuscript preparation.

IVPhD, Full Professor, Department of Experimental Surgery, UEPA, Belem-PA, Brazil. Conception, design and scientific content of the study; critical revision.

\section{Abstract}

Purpose: To evaluate the effects of hypertonic saline solution associated to remote ischemic perconditioning in liver ischemia/reperfusion injury in rats.

Methods: 25 male rats (Wistar) were distributed into five groups: Sham group (S); Ischemia/ Reperfusion group (I/R) with 30 minutes of liver ischemia; Remote ischemic perconditioning group (Per) with three cycles of 10 minutes of I/R performed during liver ischemia; Hypertonic saline solution group (HSS) treated with hypertonic saline solution ( $4 \mathrm{ml} / \mathrm{kg})$; Remote ischemic perconditioning + Hypertonic saline solution group (Per+HSS) with both treatments.

Results: Per+HSS group showed a lower degree of liver dysfunction in relation to I/R group, whereas the technique of remote ischemic perconditioning isolated or associated with saline solution significantly improved liver function and reduced histological damage.

Conclusion: Remote ischemic perconditioning associated or not to saline solution promoted reduction of acute liver injury induced by ischemia/reperfusion.

Key words: Ischemia. Reperfusion. Saline Solution, Hypertonic. Liver. Rats. 


\section{- Introduction}

Ischemia/reperfusion (I/R) injury take place when the blood supply to a tissue is blocked for a certain time (ischemia) and then restored (reperfusion) ${ }^{1}$. Ischemia causes anoxia which is the basis of ischemic injury and prepares the affected area for later reperfusion damage. $I / R$ increases the production of reactive oxygen species (ROS) in the affected tissue, leading to progressive damage, lipid peroxidation, and mitochondrial injury. This event contributes to morbimortality and the physiopathology of many diseases. In this regard, many studies have been made for the better comprehension of $I / R$, as well as to find new effective therapies against the ischemia injurious effects ${ }^{1,2}$.

One of the most promising therapies is the ischemic conditioning (IC), consisting of short alternating cycles of ischemia and reperfusion ${ }^{3}$. These cycles can be induced before (preconditioning), during (perconditioning) or after (postconditioning) the main ischemic event. This strategy was proven to have a protective effect against the I/R injury, showing an increase of the intracellular antioxidants, biochemical changes in tissues and activation of cell signaling cascades ${ }^{4}$. This protective effect was seen in many organs, such as brain, heart, kidney and liver ${ }^{5}$.

When it comes to hepatic ischemia, it is important to highlight that the Kupffer cells are perhaps the most important producer of ROS, during the ischemic stress that occurs during the cold preservation of transplantation ${ }^{6}$. A general lack of appreciation of the details of the hepatic $\mathrm{I} / \mathrm{R}$ led to studies providing more detail into the timing and compartmentalization of $I / R^{6,7}$. Another important possibility sees the Kupffer cells, as mediators of glutathione oxidation. This happens because the ROS generated by Kupffer cells has been demonstrated to be the superoxide anion radical, and selective inhibition of Kupffer cells has been shown to ameliorate I/R further emphasizing the role of ROS derived from these cells ${ }^{8}$. In this way, there is a huge importance of $I / R$ in the hepatic tissue, and many strategies to reduce the ROS damage has been used, but there are few studies that associate the IC specifically for this purpose.

Many experimental I/R hepatic studies verified important aspects, such as the necrosis which affects extensive areas of parenchymal cells consistent with the massive release of alanine transaminase (ALT) in serum, indicate that necrosis is the main cause of liver injury during $I / R^{9-11}$. Other studies that analyzed proapoptotic factors, displayed a downregulation of the Bax and cleaved Caspase-3 expression, when associated with the ischemic perconditioning, having less tissue damage ${ }^{12}$. This point highlights the importance of the IC and its protective effects, so that in the future it may be used as a clinical strategy to reduce the I/R repercussions.

\section{- Methods}

All experiments were performed in accordance with Brazilian law for scientific use of animals, and this project was formally approved by the Committee of Ethics in Animal Experimentation of Universidade Estadual do Pará (Protocol 01/2014).

Twenty-five adult male Wistar rats aged 10-12 weeks (250-350g), were obtained from Evandro Chagas Institute. The rats were maintained with free access to regular food and water, at $22 \pm 1^{\circ} \mathrm{C}$ under a 12 -h light/dark cycle.

\section{Experimental protocol}

The animals were randomly distributed into five experimental groups, each with five rats: sham group were submitted to all operative procedures, except vessels occlusion. I/R group were undergoing 30-minutes of ischemia and 72 hours of reperfusion. Remote 
ischemic perconditioning group (Per) were submitted to three cycles of 10-minutes of $\mathrm{I} / \mathrm{R}$ with a tourniquet on left hind $\operatorname{limb}^{13}$. Hypertonic saline solution (HSS) group received i.v. administration of $4 \mathrm{ml} / \mathrm{kg}^{14}$ hypertonic saline solution $7.5 \%$ after ischemic period. Remote ischemic perconditioning + HSS group (Per+HSS) received both treatments (Figure 1).

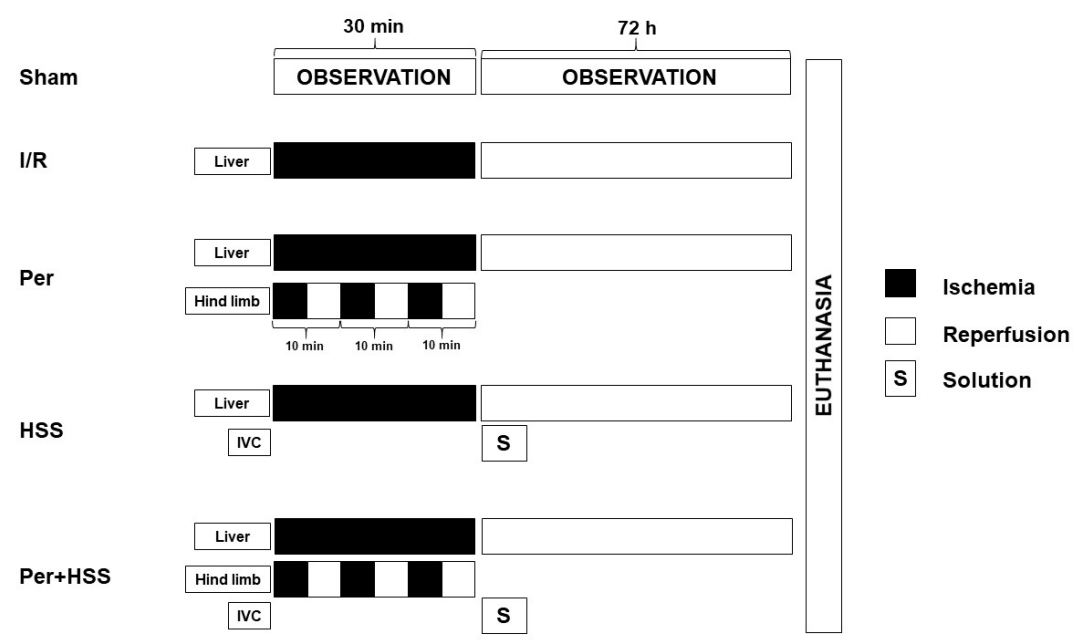

Figure 1 - Procedures between groups. IVC - inferior vena cava.

The rats were fasted overnight before the experiments, but were given free access to water. They were weighed and anesthetized using an intraperitoneal injection of ketamine hydrochloride $10 \%$ and xylazine hydrochloride $2 \%(70 \mathrm{mg} / \mathrm{kg}$ and $10 \mathrm{mg} / \mathrm{kg}$, respectively). During the operations, additional doses were administered if necessary.

\section{Surgical procedure}

A midline incision was made after shaving the abdomen, and the abdominal cavity was then exposed with the aid of retractors. Next, the left hepatoduodenal ligament containing the hepatic artery, portal vein, and bile duct of the left lateral and median liver lobes was clamped for $30 \mathrm{~min}^{15}$ with a microvascular clamp to induce partial (70\%) warm ischemia. Thereafter, the clip was removed to initiate hepatic reperfusion, and the abdominal cavity was closed. The rats were subjected to warm ischemia for 30 minutes followed by 72 hours of reperfusion ${ }^{16}$. The animals were then euthanized by overdose of ketamine hydrochloride and xylazine hydrochloride injection (triple dose of anesthetic) at the end of the reperfusion period. Liver tissues and blood samples were collected for analysis.

\section{Laboratory measurements}

Blood samples were obtained from inferiorvena cava at the end of the experimental protocol and centrifuged at $3000 \mathrm{rpm}$ for $10 \mathrm{~min}$ to obtain serum, which was immediately stored at -80 으. Serum aspartate aminotransferase (AST), alanine aminotransferase (ALT) and albumin levels were determined using ultraviolet spectrophotometric and enzymatic assays.

\section{Histologic examination}

Liver tissues for histologic examination were sampled from the left and median liver lobes at the end of the experimental protocol. The specimens were fixed in a $10 \%$ buffered formaldehyde solution, embedded in paraffin, and stained with hematoxylin and eosin. The tissue samples were sectioned into 5-mm-thick pieces for analysis. Histologic examination was performed based on randomly selected tissue 
sections using the scoring system proposed by Suzuki et al. ${ }^{17}$; specifically, the degree of sinusoidal congestion (none, minimal, mild, moderate, or severe), liver cell vacuolization (none, minimal, mild, moderate, or severe), and necrosis (none, single cell necrosis, $<30 \%, 30 \%$ $60 \%$, or $>60 \%$ ) in the tissues was determined. The histologic changes were scored from 0 to 4 , and the total score, ranging from 0 to 12 , was determined for each sample. All the sample slides were evaluated by the same pathologist, who was blinded to the corresponding control samples.

\section{Statistical analysis}

BioEstat 5.4 was used and to confirm normal distribution samples by KolmogorovSmirnov test. Data are expressed as means \pm SE. ANOVA with post hoc Tukey test was applied to renal function and oxidative stress, whereas the histopathological parameters by KruskalWallis with post hoc Newman-Keuls. Values of $p<0.05$ were considered statistically significant.

\section{Results}

Compared to Sham group, I/R showed a statistically significant in AST $(p=0.035)$,
ALT $(p=0.012)$ and albumin $(p=0.033)$ levels in blood sample. There was a statistically significant reduction between Per and Per+HSS in accordance to $\mathrm{I} / \mathrm{R}$ group observed in AST ( $p=0.023$ and $p=0.015$, respectively) and ALT $(p=0.032$ and $p=0.025)$ levels. Furthermore, perconditioning $(p=0.027)$ and Per+HSS $(p=0.019)$ group were statistically significant compared to I/R in albumin levels (Table 1 ).

Table 1 - AST, ALT and albumin serum levels according to groups.

\begin{tabular}{llll} 
Groups & AST (U/L) & ALT (U/L) & $\begin{array}{l}\text { Albumin } \\
\text { (g/dl) }\end{array}$ \\
\hline Sham & $20.6 \pm 11.7$ & $39.3 \pm 5.3$ & $4.8 \pm 0.2$ \\
I/R & $268.3 \pm 29.1^{\mathrm{a}}$ & $279.2 \pm 97.4^{\mathrm{a}}$ & $2.4 \pm 0.1^{\mathrm{a}}$ \\
Per & $139.5 \pm 13.5^{\mathrm{b}}$ & $140.6 \pm 14.7^{\mathrm{b}}$ & $3.6 \pm 0.1^{\mathrm{b}}$ \\
HSS & $169.5 \pm 26.5$ & $226.1 \pm 20.4$ & $2.9 \pm 0.2^{2}$ \\
Per+HSS & $118.3 \pm 16.4^{\mathrm{b}}$ & $110.6 \pm 10.3^{\mathrm{b}}$ & $4.3 \pm 0.2^{\mathrm{b}}$ \\
\hline
\end{tabular}

Data are expressed as means \pm SD. Teste ANOVA (Tukey). ${ }^{a} p<0.05$ vs. grupo Sham. ${ }^{b} p<0.05$ vs. grupo I/R.

In addition, there was statistically significant difference between Perconditioning and Per+HSS group in all microscopic parameters: sinusoidal congestion, cell vacuolization and necrosis (Figure 2), compared to I/R group.

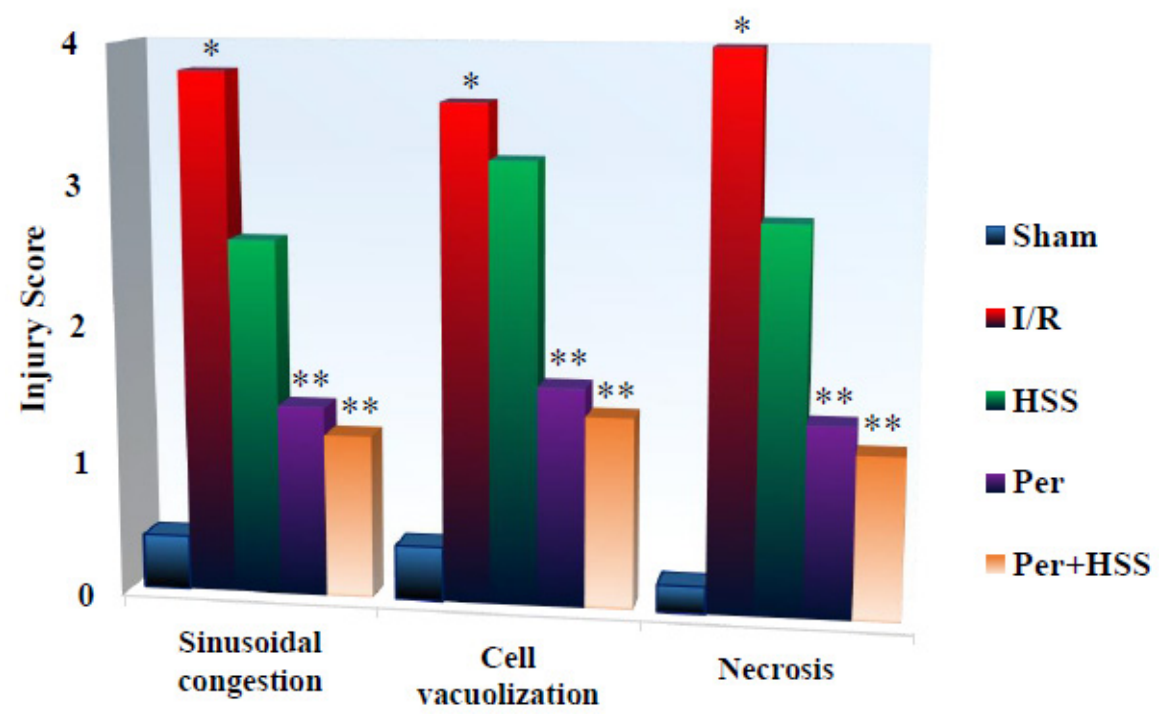

Figure 2 - Histopathological analysis according to groups. ${ }^{*} p<0.05$ vs. Sham group; ${ }^{* *} p<0.05$ vs. I/R group. Kruskal-Wallis (Newman-Keuls) test. Source: Protocol research. 


\section{- Discussion}

$\mathrm{I} / \mathrm{R}$ presented significantly higher serum levels of AST and ALT as well evidence of histopathologic damage when compared to Sham group, demonstrating that the experimental model was effect in promoting injury to hepatocytes. A decreasing in liver function was also observed in I/R group.

Our results show that Per was effective in reduce $I / R$ injury. This technique lowered damage to hepatocytes and improved liver function, while HSS did not demonstrate a protective on liver $I / R$ injury. There was not additive protection when Per and HSS administration were held together.

The protective effect of perconditioning on liver I/R was reported by Czigány et al. ${ }^{18}$ that performed four cycles of occlusion and four cycles of reperfusion, clamping infrarenal aorta.

Perconditioning leads to a parasympathetic neural response which was identified as one of its effector mechanisms, reducing nonperfusion lesion by vasospasm mechanism and contributing to the reestablishment of blood flow in microcirculation of the organ submitted to $\mathrm{I} / \mathrm{R}$ injury ${ }^{19}$.

Moreover, application of ischemic perconditioning to a remote organ can induce the release of humoral factors such as adenosine, bradykinin, and opioids, which under local innervation, would trigger activation of neural pathways that promotes tissue protection ${ }^{19}$.

Further studies are necessary to evaluate the effects of different protocols of perconditioning, using alternative times of occlusion as well more cycles of $\mathrm{I} / \mathrm{R}$ in order to find out a better protocol to apply this technique.
In literature there are some reports that have found promising results in other possibilities of I/R cycles. Costa et al. ${ }^{20}$, showed that four cycles of 05 minutes of hind limb ischemia followed by 05 minutes of hind limb reperfusion, lasting 40 minutes, reduced ROS formation and lowered transaminases serum level.

As a limitation of our research, we did not evaluate the early effects of perconditioning and HSS on the I/R injury. In future studies we can analyze oxidative parameters minutes after the beginning of reperfusion, such as TBARs, TEAC, SOD and catalase. Long-term effects of both treatments on liver recovery after injury and mortality rate have also not been tested.

\section{Conclusions}

The protective effect of remote ischemic perconditioning, when isolated or associated to hypertonic saline solution, was demonstrated in reduction of liver ischemia/ reperfusion injury. However, there was no difference between Per and Per+HSS groups.

\section{References}

1-Ma Z, Xin Z, Di W, Yan X, Li X, Reiter RJ, Yang $Y$. Melatonin and mitochondrial function during ischemia/reperfusion injury. Cell Mol Life Sci. 2017;74(21):3989-98. doi: 10.1007/ s00018-017-2618-6.

2-Covington S, Bauler L, ToledoPereyra L. Akt: a therapeutic target in hepatic ischemia-reperfusion injury. J Invest Surg. 2016;30(1):47-55. doi: 10.1080/08941939.2016.1206999.

3-Brandli A. Remote limb ischemic preconditioning: a neuroprotective technique in rodents. J Vis Exp. 2015;(100):e52213. doi: 10.3791/52213.

4-Karatzas T, Neri A, Baibaki M, Dontas I. Rodent models of hepatic ischemiareperfusion injury: time and percentage- 
related pathophysiological mechanisms. J Surg Res. 2014;191(2):399-412. doi: 10.1016/j.jss.2014.06.024.

5-Szijártó A. Szabad gyökök és a máj ischaemiás-reperfúziós károsodása. Orvosi Hetilap. 2015;156(47):1904-7. doi: 10.1556/650.2015.30305.

6-Jaeschke H, Bautista AP, Spolarics Z, Spitzer JJ. Superoxide generation by Kupffer cells and priming of neutrophils during reperfusion after hepatic ischemia. Free Radic Res Commun. 1991;15:277-84. doi: 10.3109/10715769109105223.

7-Caldwell-Kenkel JC, Currin RT, Tanaka Y, Thurman RG, Lemasters JJ. Kupffer cell activation and endothelial cell damage after storage of rat livers: effects of reperfusion. Hepatology. 1991;13:83-95. doi: 10.1002/ hep.1840130113.

8-Shibuya H, Ohkohchi N, Seya K, Satomi S. Kupffer cells generate superoxide anions and modulate reperfusion injury in rat livers after cold preservation. Hepatology. 1997;25:356-60. doi: 10.1053/jhep.1997. v25.pm0009021947.

9-Araújo Júnior $R$, Silva Júnior $R$, Vasconcelos M, Guimarães S, Vasconcelos P, Garcia J. Preconditioning with L-alanyl-glutamine reduces hepatic ischemia-reperfusion injury in rats. Acta Cir Bras. 2011;26(Suppl 1):8-13. doi: 10.1590/S0102-86502011000700003.

10-Knudsen A, Kannerup A, Grønbæk $H$, Dutoit S, Nyengaard J, Funch-Jensen $P$, Mortensen FV. Quantitative histological assessment of hepatic ischemia-reperfusion injuries following ischemic pre and postconditioning in the rat liver. J Surg Res. 2013;180(1):e11-e20. doi: 10.1016/j. jss.2012.03.036.

11-Suyavaran A, Ramamurthy C, Mareeswaran $R$, Subastri A, Lokeswara Rao P, Thirunavukkarasu C. TNF- $\alpha$ suppression by glutathione preconditioning attenuates hepatic ischemia reperfusion injury in young and aged rats. Inflamm Res. 2014;64(1):7181. doi: 10.1007/s00011-014-0785-6.

12-ark M, Joo S, Kim B, Lee J, Kim Y, Hong M, Ahn $\mathrm{HJ}$. Remote preconditioning on rat hepatic ischemia-reperfusion injury downregulated bax and cleaved caspase-3 Expression. Transplantat Proc. 2016;48(4):1247-50. doi: 10.1016/j.transproceed.2015.12.125.

13-Yamaki VN, Gonçalves TB, Coelho JV, Pontes RV, Costa FL, Brito MV. Protective effect of remote ischemic per-conditioning in the ischemia and reperfusion-induce renal injury in rats. Rev Col Bras Cir. 2012 Dec;39(6):529-33. doi: 10.1590/S010069912012000600014.

14-Attuwabi B, Kozar, RA, Gates, KS, MooreOlufemi S, Sato N, Weisbrodt NW, Moore FA. Hypertonic saline prevents inflammation, injury, and impaired intestinal transit after gut ischemia/reperfusion by inducing heme oxygenase 1 enzyme. J Trauma. 2004 Apr;56(4):749-58. doi: 10.1097/01. TA.0000119686.33487.65.

15-Reiling J, Bridle KR, Gijbels M, Schaap FG, Jaskowski L, Santrampurwala N, Britton LJ, Campbell CM, Olde Damink SW, Crawford $\mathrm{DH}$, Dejong $\mathrm{CH}$, Fawcett J. Low-dose lipopolysaccharide causes biliary injury by blood biliary barrier impairment in a rat hepatic ischemia/reperfusion model. Liver Transpl. 2017 Feb;23(2):194-206. doi: 10.1002/It.24681.

16-Fujii T, Obara $H$, Matsubara K, Fujimura $\mathrm{N}$, Yagi $\mathrm{H}$, Hibi T, Abe $\mathrm{Y}$, Kitago $M$, Shinoda M, Itano O, Tanabe M, Masugi Y, Sakamoto M, Kitagawa Y. Oral administration of cilostazol improves survival rate after rat liver ischemia/reperfusion injury. J Surg Res. 2017 Jun 1; 213:207-14. doi: 10.1016/j. jss.2017.02.020.

17-Suzuki S, Toledo-Pereyra LH, Rodriguez FJ, Cejalvo D. Neutrophil infiltration as an important factor in liver ischemia and reperfusion injury. Modulating effects of FK506 and cyclosporine. Transplantation. 1993;55:1265-72. PMID: 7685932.

18-Czigány Z, Turóczi Z, Ónody $P$, Harsányi L, Lotz G, Hegedüs V, Szijártó A. Remote ischemic perconditioning protects the liver from ischemia-reperfusion injury. J Surg Res. 2013 Dec 31;185(2):605-13. doi: dx.doi. org/10.1016/j.jss.2013.07.018.

19-Lim SY, Yellon DM, Hausenloy DJ. The neural and humoral pathways in remote limb ischemic preconditioning. Basic Res Cardiol. 2010 Sep;105(5):651-5. doi: 10.1007/ s00395-010-0099-y.

20-Costa FLS, Yamaki VN, Gonçalves TB, 
Coelho JV, Percário S, Brito MV. Combined remote ischemic perconditioning and local postconditioning on liver ischemia- reperfusion injury. J Surg Res. 2014 Nov 30;192(1):98-102. doi: dx.doi.org/10.1016/j. jss.2014.05.046.

\section{Correspondence:}

Rubens Fernando Gonçalves Ribeiro Júnior

Avenida Marquês de Herval, 1823

66087-320 Belém - PA Brasil

Tel.: (+55 91)98133-7502

rubensfernandojr@gmail.com

Received: July 25, 2017

Review: Sept 26, 2017

Accepted: Oct 27, 2017
Conflict of interest: none

Financial source: none
${ }^{1}$ Research performed at Laboratory of Experimental Surgery, Universidade Estadual do Pará (UEPA), Belem-PA, Brazil. 